\title{
Paying for the health workforce
}

\section{Payment systems should be considered more often as a policy intervention to improve health system performance}

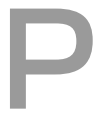

ayment and funding are often regarded as administrative transfers; and yet, funding is rarely provided without strings attached. Where funding and remuneration are made conditional on certain behaviours (eg, working a set number of hours, seeing a certain number of patients, undertaking specific tasks or tasks of a certain standard, or "doing a good job"), financial incentives are created. These can have material impacts on health professionals' behaviour, access to health care, performance of the health system and population health. Changing the level and method by which health professionals are paid, therefore, has the potential to be used to redress health workforce shortages and the maldistribution of health professionals across specialties, sectors and geographic areas, and to improve the quality and costs of the health care that is provided.

Many countries have experienced recent growth in payfor-performance schemes and changes in the level and methods of remuneration of health professionals, mainly doctors. ${ }^{1,2}$ Health policy focuses less on how salaried employees, such as nurses, are paid, although arguments about the importance and role of pay apply equally, given the current growth in the number of salaried employees such as practice nurses. ${ }^{3}$

A key issue that often prevents research in this area, and therefore prevents an evidence base from developing, is that changing the level and method of payment for health professionals is contentious. National data on earnings are difficult to come by. Reform is viewed as risky by politicians, given the often protracted and difficult industrial negotiations that may be required because health professionals view change as not only a potential threat to their earnings but also to their autonomy. The Australian report on realigning the relativities of rebates in the Medicare Benefits Schedule is one example where the results were not acted upon because of strong professional interests favouring the status quo. ${ }^{4}$ In practice, many changes to doctors' remuneration in other countries have not resulted in a loss in earnings and, indeed, have often delivered large gains in earnings, such as through the Quality and Outcomes Framework for general practitioners in the United Kingdom. ${ }^{1}$ The issue for governments and employers is the extent to which the additional payments result in improved performance or increased access to health care. ${ }^{5}$

\section{What does the health workforce cost?}

There is no single source of information on the national cost of the health workforce in Australia. The variety of state, federal and private employers, insurers and patients who provide funds makes it difficult to separate out remuneration of the health workforce from other revenue (non-capital) expenditure. The opportunity costs of the health workforce should be a measure of the value of health professionals' time, usually their gross (before tax) personal earnings, and any on-costs for employees (eg, superannuation) incurred by employers. This is difficult to estimate for self-employed health professionals as they may also receive a share of profits from their business as personal income. The main source of data is the Australian Institute of Health and Welfare (AIHW), which splits health expenditure into a number of sources. ${ }^{6,7}$ However, payments from Medicare and private health insurers are gross payments and will include an element of non-salary practice expenses, and so may overestimate health professionals' personal earnings. The AIHW supplies aggregated data and does not provide detailed information on the source of its estimates. For example, it is not clear whether AIHW data include the costs of salaried health professionals and administrative staff in private sector organisations, such as small businesses in general practice and allied health. Although Australian census data include the earnings of a range of health professional groups, this is by category, with the highest salary category including earnings over $\$ 100000$ per annum, so they do not provide good estimates for many groups such as medical practitioners, dentists and senior managers who may earn well above this level. Data on the salary bills for companies, partnerships and trusts are available on the Australian Taxation Office website. ${ }^{8}$ They are the most comprehensive national source of data on the income and earnings of health professionals, although data are difficult to access apart from some summary data on the website. ${ }^{9}$

The opportunity cost of a new health professional does not just include their lifetime earnings, but also their training costs. However, there are no national data covering the spectrum of training from undergraduate education, prevocational training, vocational training, and training and supervision of migrants. The lack of data is very surprising - decisions are being made about training extra doctors and nurses without knowledge or evidence of the costs or the benefits in terms of improvements in population health. Training costs are borne by a mix of federal and state governments, educational institutions, and individuals paying for some or all of their own educational expenses. These funders face different sets of incentives with little coordination between them. Postgraduate training and its costs are integrated into the delivery of public hospital services, and so are difficult to separate out from the figures on the costs of public hospital staffing. Given the major growth in the number of medical students and other types of health professional, the costs of training are expected to grow substantially, with an uncertain impact on health expenditures. 


\section{Do different levels of payment matter?}

Changes in the level of pay have been shown to influence hours worked by doctors and nurses, doctors' choice of specialty, and recruitment and retention., ${ }^{3,9-12}$ The impact of higher hourly earnings is an increase in hours worked and in workforce participation. This effect is relatively small but usually statistically significant in most labour supply models for both doctors and nurses. ${ }^{3,11,13}$ There is also the possibility, but little strong evidence, of "backward bending" labour supply among doctors on relatively high incomes, where higher earnings cause a fall in hours worked as doctors prefer to spend their higher income on more leisure time. Aggregate data for Australian doctors provide weak evidence that the average number of hours worked is falling, while the costs of medical services are increasing and fewer patients are being seen. ${ }^{14}$ The effect of relative earnings on specialty choice is particularly important for doctors choosing to work in primary care, where more doctors are needed because of the growing burden of chronic disease that should be treated outside of hospitals.

How levels of pay are set can also influence recruitment and retention and, therefore, access to health services. Pay that is set under bargaining agreements and is relatively fixed across a large geographical area provides a stable income for employees, but employers are not able to alter pay in order to solve local recruitment and retention problems. Other employers compete for the skills of nurses and other health professionals, and there is evidence that when competing wage rates are high in the private sector, public hospitals experience recruitment and retention problems and higher vacancy rates, as well as higher patient mortality rates and lower quality of care..$^{15-17}$ A degree of pay flexibility could therefore ease recruitment and retention difficulties, potentially improving the health status of patients and quality of care, but at the cost of potentially higher health expenditures and increased inequity of pay between staff with similar experience. Incentives for performance are embedded in the salary scales for employees. Gaps between each increment in the scale, combined with opportunities for promotion, create financial incentive for improved performance and clearly define career trajectories. ${ }^{18}$ For some health professionals, such as practice nurses, these career structures are not well developed. Unions prefer equity of pay through "short" scales with small gaps between each increment, while employers prefer longer scales with larger gaps to encourage higher and increasing levels of performance. Evidence on these issues exists for other industries, ${ }^{18}$ but is limited for health care. The important issue is that how salaries are set and the outcome of wage or fee bargaining can have important effects on recruitment, retention, health care access, costs and population health that often go unrecognised.

Different levels of payment across geographical areas can be used to improve recruitment and retention into underserved areas. In Australia, this is a significant issue, yet careful evaluation of Australian schemes has not been conducted. Evidence is very weak and plagued by poor study design, ${ }^{19}$ resulting in a large gap in evidence in this important policy area.

\section{Do different methods of paying health professionals matter?}

There is a large body of literature examining changes in methods by which health professionals, largely doctors, are paid. Although the evidence is mixed and of variable quality, Cochrane reviews have found that different methods of payment (eg, fee-for-service, capitation, salary, and pay-for-performance or bonuses) all influence clinical behaviour and the quality of health care provided. ${ }^{20-24}$ There is an emerging consensus that fee-for-service payment does not encourage optimal care for patients with chronic disease. Recent models in Australia (eg, the Coordinated Care for Diabetes Pilot) and experience in the United States with the "patient-centred medical home", also known as "accountable care organizations", are introducing blended payments that include a capitation payment and an element of pay for performance. ${ }^{25}$ These have existed for some time in the UK for general practitioners, who now receive $25 \%$ of their earnings through the Quality and Outcomes Framework pay-forperformance scheme. ${ }^{1}$

The reported doubts about the effectiveness of schemes such as pay for performance are concerned not only with the poor methodological design of evaluative studies, but also with the poor design of the payment schemes themselves. ${ }^{26}$ Avoiding unintended and undesirable consequences (there may also be some unintended but desirable consequences ${ }^{27}$ ) can be partly achieved through careful design and implementation. For example, payments should be risk-adjusted to avoid the selection of healthy patients so providers are properly compensated for high-cost patients. ${ }^{25}$ Exception reporting, where providers can exclude patients from the denominator of payment calculations, can be avoided by paying only for the numerator; that is, a payment for each patient hitting a target, rather than for the proportion of patients hitting a target. ${ }^{28}$ Schemes should also reward for measured improvements in quality between two time periods, rather than for the achievement of a given level of quality. ${ }^{29}$

\section{Current challenges in paying health professionals}

The first long-term challenge is to reorient remuneration schemes to reward for improving the health status of patients and improving access to health care, and to recognise, especially in primary care, the need to appropriately manage the growing burden of chronic disease. Moving away from reliance on fee for service as more care needs to be provided outside of hospitals is the biggest political challenge. Historically, the only way this has occurred in other countries is by ensuring that doctors' incomes do not fall, but, more often than not, rise substantially. The challenge for governments is to ensure that such inevitable increases in expenditure are matched by improvements in population health and better access to health care. This depends on first producing better measures of organisational and system performance and also deciding which treatment interventions and behaviours should be incentivised. Current health reform 
initiatives seeking to produce data on health services performance are a belated step in the right direction.

A second challenge is to evaluate carefully any changes to remuneration levels or different types of remuneration. Opportunities for randomised trials are rare, but they are possible. In the absence of randomisation, it then becomes important to use the vast amounts of administrative data that exist. For example, it would make sense to link hospital personnel records with data on a range of risk-adjusted performance measures (eg, mortality rates, adverse events, quality of life). The linkage of data on inputs (and their costs) to outputs and outcomes is fundamental in improving efficiency, health outcomes and access to care. However, linking the characteristics of the health workforce (hours worked, qualifications, experience, pay) to quality of care and costs is still a distant dream in Australia, but it has been possible in other countries.

A third challenge relates to legal and industrial issues that determine workforce flexibility (or inflexibility). Flexibility refers to the ability to quickly change roles, scopes of practice, training paradigms, pay and conditions to respond to changes and shifts in demand, such as the growing burden of chronic disease and new technologies. This is fundamental in the private sector, and there are, undoubtedly, good reasons why the health sector is much less flexible, but these reasons should be revisited and challenged. For example, it is unclear exactly how autonomous the recently introduced Local Hospital Networks will be. The inflexibility of pay-setting arrangements may contribute to preventing the networks from responding to the incentives within activity-based funding. A further example is the many workforce innovation pilot studies of new and expanded roles of staff and new types of staff, which are being funded by Health Workforce Australia and state governments. The sustainability and rollout of successful pilots depends heavily on having a supportive and flexible industrial and legal framework in place that should be redesigned at a national rather than individual pilot level. Patient safety is a key issue in the development of new roles, but the potential loss of life and high costs caused by inflexibilities in workforce roles and payment systems also needs to be considered. Trade-offs exist but are seldom examined.

The establishment of Health Workforce Australia in 2010 has given a clearer policy focus to health workforce issues. Although Health Workforce Australia is partly responsible for paying for some undergraduate clinical training, other issues about pay and remuneration are not currently within their remit but cut across a number of other state and federal government departments and a range of other organisations responsible for determining the amount and method of health professional remuneration (eg, the private and not-for-profit sectors). The final and most significant challenge is, therefore, to provide national leadership in reforming the institutional structures that influence the payment and remuneration of health professionals to achieve better health outcomes for the population at lower cost.

Acknowledgement: I am funded by an Australian Research Council Future Fellowship.

Competing interests: The Melbourne Institute of Applied Economic and Social Research has received funding from Health Workforce Australia as part of the National Health Workforce Planning and Research Collaboration.
Provenance: Commissioned; externally peer reviewed.

1 Doran T, Fullwood C, Gravelle H, et al. Pay-for-performance programs in family practices in the United Kingdom. N Engl J Med 2006; 355: 375-384

2 Rosenthal MB, Landon BE, Howitt K, et al. Climbing up the pay-forperformance learning curve: where are the early adopters now? Health Aff (Millwood) 2007; 26: 1674-1682

3 Antonazzo E, Scott A, Skatun D, Elliott RF. The labour market for nursing: a review of the labour supply literature. Health Econ 2003; 12: 465-478.

4 National Centre for Classification in Health. Professional relativities study: final report. Sydney: NCCH, 2000.

5 Gillam S. Should the quality and outcomes framework be abolished? Yes. BMJ 2010; 340: c2710.

6 Australian Institute of Health and Welfare. Australian hospital statistics 2008-09. Canberra: AlHW, 2010. (AlHW Cat. No. HSE 84; Health Services Series No. 34.) http://www.aihw.gov.au/publicationdetail/?id=6442468373 (accessed May 2012)

7 Australian Institute of Health and Welfare. Health expenditure Australia 2008-09. Canberra: AlHW, 2010. (AlHW Cat. No. HWE 51 Health and Welfare Expenditure Series No. 42.) http:// www.aihw.gov.au/publication-detail/?id=6442472450 (accessed May 2012).

8 Australian Taxation Office. Taxation statistics 2007-08. Canberra: ATO 2010. http://www.ato.gov.au/content/00225078.htm (accessed May 2012)

9 Baltagi BH, Bratberg E, Holmås TH. A panel data study of physicians' labor supply: the case of Norway. Health Econ 2005; 14: 1035-1045.

10 Ikenwilo D, Scott A. The effects of pay and job satisfaction on the labour supply of hospital consultants. Health Econ 2007; 16: 1303-1318.

11 Sæther EM. Physicians' labour supply: the wage impact on hours and practice combinations. Labour 2005; 19: 673-703. doi: 10.1111/j.14679914.2005.00317.x.

12 Thornton J. Physician choice of medical specialty: do economic incentives matter? Appl Econ 2000; 32: 1419-1428. doi: 10.1080/ 00036840050151494.

13 Shields MA. Addressing nurse shortages: what can policy makers learn from the econometric evidence on nurse labour supply? Econ J 2004; 114: F464-F498. doi: 10.1111/j.1468-0297.2004.00255.x.

14 Scott A. The productivity of the health workforce. Aust Econ Rev 2006; 39: 312-317. doi: 10.1111/j.1467-8462.2006.00420.x.

15 Twigg D, Duffield C, Thompson PL, Rapley P. The impact of nurses on patient morbidity and mortality - the need for a policy change in response to the nursing shortage. Aust Health Rev 2010; 34: 312-316.

16 Propper C, Van Reenen J. Can pay regulation kill? Panel data evidence on the effect of labor markets on hospital performance. J Polit Econ 2010; 118: 222-273.

17 Elliott RF, Ma AH, Scott A, et al. Geographically differentiated pay in the labour market for nurses. J Health Econ 2007; 26: 190-212.

18 Prendergast C. The provision of incentives in firms. J Econ Lit 1999; 37 7-63.

19 Bärnighausen T, Bloom DE. Financial incentives for return of service in underserved areas: a systematic review. BMC Health Serv Res 2009; 9: 86

20 Flodgren G, Eccles MP, Shepperd S, et al. An overview of reviews evaluating the effectiveness of financial incentives in changing healthcare professional behaviours and patient outcomes. Cochrane Database Syst Rev 2011; (7): CD009255.

21 Giuffrida A, Gosden T, Forland F, et al. Target payments in primary care: effects on professional practice and health care outcomes. Cochrane Database Syst Rev 2000; (4): CD000531.

22 Scott A, Sivey P, Ait Ouakrim D, et al. The effect of financial incentives on the quality of health care provided by primary care physicians. Cochrane Database Syst Rev 2011; (9): CD008451.

23 Gosden T, Forland F, Kristiansen I, et al. Impact of payment method on behaviour of primary care physicians: a systematic review. J Health Serv Res Policy 2001; 6: 44-55.

24 Gosden T, Forland F, Kristiansen IS, et al. Capitation, salary, fee-forservice and mixed systems of payment: effects on the behaviour of primary care physicians. Cochrane Database Syst Rev 2000; (3): CD002215.

25 Merrell K, Berenson RA. Structuring payment for medical homes. Health Aff (Millwood) 2010; 29: 852-858.

26 Campbell SM, Scott A, Parker RM, et al. Implementing pay-forperformance in Australian primary care: lessons from the United Kingdom and the United States. Med J Aust 2010; 193: 408-411.

27 Sutton M, Elder R, Guthrie B, Watt G. Record rewards: the effects of targeted quality incentives on the recording of risk factors by primary care providers. Health Econ 2010; 19: 1-13.

28 Twardella $\mathrm{D}$, Brenner $\mathrm{H}$. Effects of practitioner education, practitioner payment and reimbursement of patients' drug costs on smoking cessation in primary care: a cluster randomised trial. Tob Control 2007; 16: 15-21.

29 Young D, Scott A, Best JD. For love or money? Changing the way GPs are paid to provide diabetes care. Med J Aust 2010; 193: 67-68. 